\title{
Ureteral Penetration Caused by Drilling During Internal Pelvic Bone Fixation: Delayed Recognition
}

\author{
Yu Seob Shin, Jong Hyuk Park ${ }^{1}$, Omer A. Raheem², Young Beom Jeong, Hyung Jin Kim, Young Gon Kim \\ Departments of Urology and ' $\mathrm{Orthopedic} \mathrm{Surgery,} \mathrm{Chonbuk} \mathrm{National} \mathrm{University} \mathrm{Medical} \mathrm{School,} \mathrm{Jeonju,} \mathrm{Korea;}$ \\ ${ }^{2}$ Division of Urology, Department of Surgery, University of California San Diego, CA, USA
}

\begin{abstract}
A 49-year-old man was referred to our department with profuse serous fluid discharge from a Penrose drain after undergoing internal fixation with metal screws for multiple pelvic bone fractures. A definite ureteral penetration was identified that was orientated from the lateral to the medial aspect of the right distal ureter. The patient was surgically treated with excision of the $2-\mathrm{cm}$ injured ureteral segment, end-to-end ureteroureterostomy, and double J ureteral stent placement. To our knowledge, a penetrating ureteral injury caused by bone drilling has not been reported previously in the published literature. This case shows that surgeons who do pelvic surgery, including orthopedic surgeons, should be familiar with the anatomical relationship of the ureter and its potential injuries.
\end{abstract}

Keywords: Ureter; Drilling; Injury

Iatrogenic injury of the ureter has been extensively documented in association with urogynecological and colorectal surgery [1]. However, little is known about orthopedic-associated ureteral injuries. We report the first case of ureteral injury following orthopedic internal pelvic bone fixation with metal bone screws and describe in detail its clinical presentation, diagnosis, and treatment.

\section{CASE REPORT}

A 49-year-old man was referred to our department with persistent serous fluid discharge via a Penrose drain that had been intraoperatively placed into the operation site and had remained until postoperative day $10 \mathrm{after}$ orthopedic internal fixation with metal screws for multiple pelvic bone fractures. The creatinine and blood urea nitrogen values of the discharged fluid were $25.56 \mathrm{mg} / \mathrm{mL}$ and $86 \mathrm{mg} / \mathrm{mL}$, respectively. Subsequently, intravenous urography was performed, which showed urinary extravasation arising from the right distal ureter suspicious of a right distal ureteric injury (Fig. 1). Renal ultrasonography was also performed, which confirmed grade I hydronephrosis of the right kidney. Following this, a percutaneous nephrostomy (PCN) tube was successfully inserted to divert the urine output into an external drainage bag. To further specify the location and severity of the right distal ureteric injury, an antegrade nephrostogram was performed via the PCN tube, which clearly demonstrated extravasation of contrast material around the right distal ureter (Fig. 2). However, an antegrade attempt to internalize the right ureter by placement of a double J ureteric stent failed. After detailed discussion with the patient, it was decided to proceed with an emergent reconstructive operation to repair the right distal ureteric injury. A midline laparotomy was performed to obtain adequate surgical exposure of the injured right ureter. After careful dissection, the right ureter was found to be displaced medially by a well-formed urinoma secondary to urinary leakage along the right pelvic side wall. In addition, reactive inflammatory changes adjacent to the injured ureter had resulted in adhesions that made ureteric dissection difficult. Two
Corresponding author: Young Beom Jeong

Department of Urology, Chonbuk National University Medical School,

567 Baekje-daero, Deokjin-gu, Jeonju 561-756, Korea

Tel: +82-63-250-1911 / Fax: +82-63-250-1564 / E-mail: ybjeong@jbnu.ac.kr

Submitted: November 8, 2012 / Accepted after revision: June 5, 2013
This is an Open Access article distributed under the terms of the Creative Commons Attribution Non-Commercial License (http://creativecommons.org/licenses/by-nc/3.0/) which permits unrestricted non-commercial use, distribution, and reproduction in any medium, provided the original work is properly cited. 


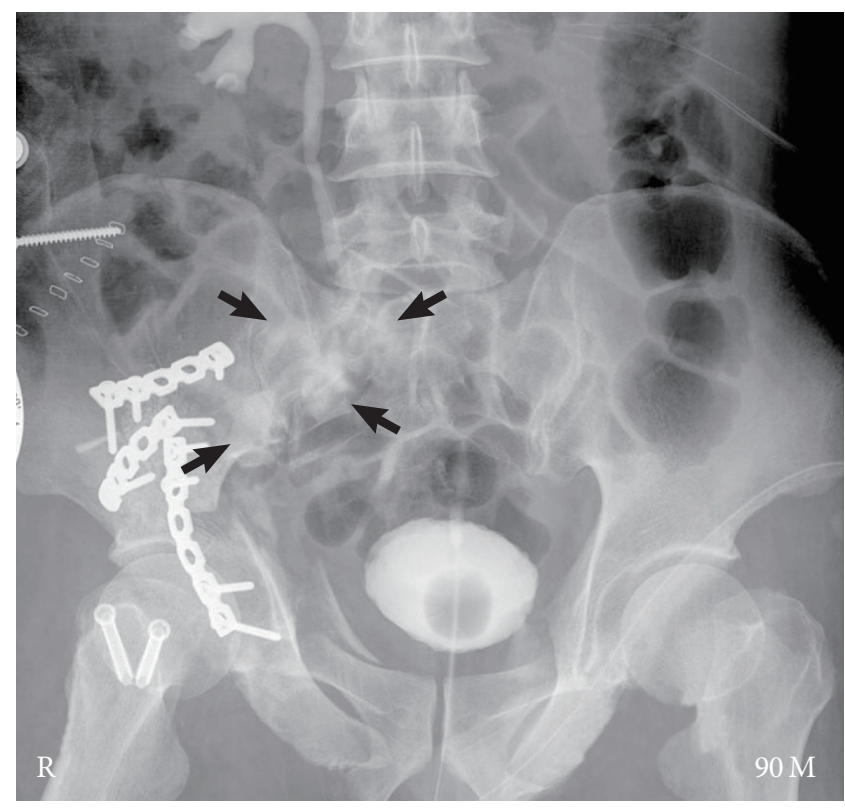

Fig. 1. Delayed image of intravenous urography showing extensive extravasation of the contrast media (arrows) from the right ureter and no visualization of the right distal ureter.

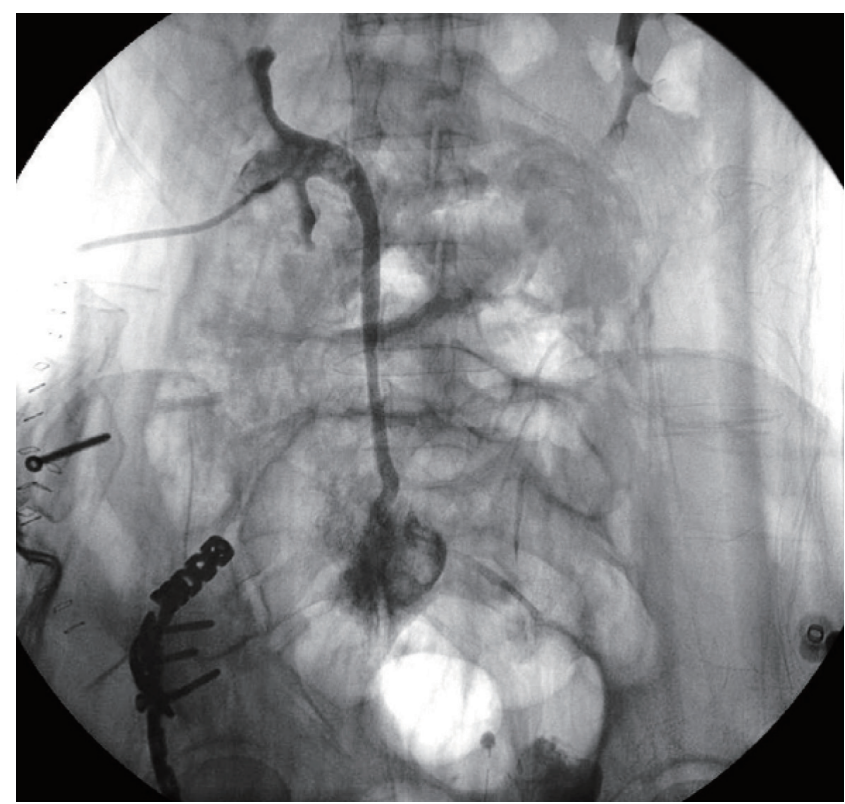

Fig. 2. Antegrade pyelography showing extravasation of the contrast media in the right distal ureter.

penetrating holes leaking urine at the same level of the right distal ureter were intraoperatively identified. After complete evacuation of the urinoma, approximately $2 \mathrm{~cm}$ of the injured ureteral segment was excised and an additional ureteral dissection was made so that tension-free ureteral anastomosis could

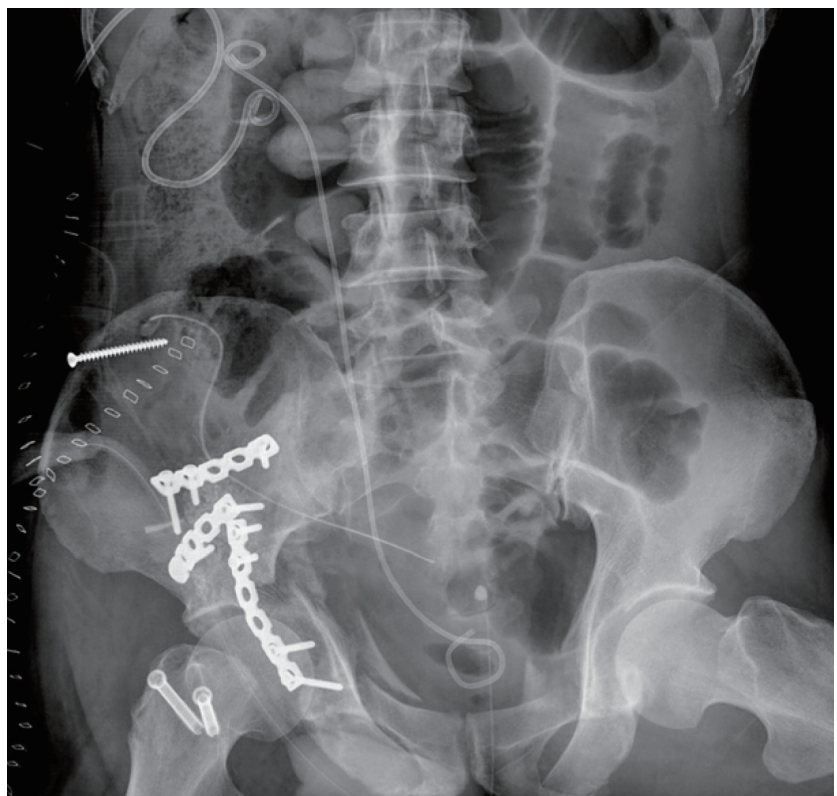

Fig. 3. Postoperative KUB (kidney, ureter, and bladder) radiograph showing D-J stent placement in the right ureter.

be safely achieved. Eventually, an end-to-end ureteroureterostomy was performed over a 6-French double J ureteral stent (Fig. 3). The patient recovered fully without complications or adverse sequelae.

\section{DISCUSSION}

Injury to the ureter during pelvic orthopedic surgery is exceedingly rare. Iatrogenic ureteral injury complicates $0.5 \%$ of benign pelvic urological, gynecological, obstetric, and general surgical procedures [1]. To date, a few reports of ureteral avulsion caused by orthopedic surgeries have been published [2,3]. However, a through-and-through ureteral penetrating injury that was suspected to be caused by machinery drilling during pelvic bone fixation has not been published previously in the literature. In this patient, penetration of a metal screw through the ureter is suspected as the cause of the injury. However, the exact mechanism of injury cannot be easily explained. For example, it is possible that the direct placement of the metal screws themselves could lead to penetrating ureteric injury; however, these screws do not have strong enough forwarding shear force to cause such ureteric injury. Structurally and owing to anatomical configurations, the ureter can readily move side to side and to a lesser extent upward and downward when pushed or pulled by a direct mechanical force such as ureteroscopy or ureteral stent insertion. 
Therefore, we suspect the main cause of the ureteric penetration could be a machinery drill used on the pelvic bone because such an instrument can generate instantaneous moving power. Adding to this, we can also hypothesize that the direction of the penetration was from the lateral to the medial side, which was primarily due to the original operation site being lateral to the injured ureter. In addition, the medial structures of the ureter, such as the peritoneum and bowel, were intact. This suggests that the injury could have been caused during drilling because the direction of the ureteric injuries was parallel in both direction and configuration to that of the bone metal screw placed in the pelvic bone.

Important factors when deciding on the treatment method in ureteric injury are the extent and level of injury, time to recognition, and associated injury. Of these, recognition time is the most important factor in deciding how to manage the injury. If the diagnosis is made within the first 5 days after the primary insult, urologists prefer to proceed with immediate surgical repair. However, if the diagnosis is made 6 days or longer after the trauma, many urologists would place a PCN tube or double J ureteral stent in view of contemplating a delayed definitive repair [4]. If the ureteral injury is partial, that is, the ureteral patency is sustained, the first attempt to treat the injury should be placement of an indwelling double J ureteric stent whether it is antegrade or retrograde $[4,5]$. Failing this, a PCN tube can be very useful in diverting the urine output as a temporary measure for a period of 3 months to allowing sufficient time to resolve periureteral inflammatory adhesion, after which delayed reconstructive surgery can be carefully planned and executed. In this patient, we could not place a retrograde ureteral stent because the lithotomy position was impossible owing to the recently performed orthopedic surgery. Therefore, we first elected to place the ureteral stent via the PCN tract but failed. Subsequent- ly, an emergent reconstructive operation was performed owing to medicolegal problems despite the somewhat delayed recognition of the injury.

This case shows that the possibility of ureteral injury exists during internal fixation with metal bone screws for iliac bone fractures. Although the diagnosis of the event in this case was delayed until postoperative day 10 , satisfactory results including preservation of kidney function were achieved.

In conclusion, we emphasize that surgeons who operate on the pelvic cavity and adjacent structures should be familiar with the anatomy of the ureter and its pelvic course so that inadvertent ureteric injury can be avoided.

\section{CONFLICT OF INTEREST}

No potential conflict of interest relevant to this article was reported.

\section{REFERENCES}

1. Preston JM. Iatrogenic ureteric injury: common medicolegal pitfalls. BJU Int 2000;86:313-7.

2. Waters E, Bouchier Hayes DM, Hickey D. Delayed presentation of ureteric injury after thermal insult at total hip replacement. Br J Urol 1998;82:594.

3. Trinchieri A, Montanari E, Salvini P, Berardinelli L, Pisani E. Renal autotransplantation for complete ureteral avulsion following lumbar disk surgery. J Urol 2001;165:1210-1.

4. McAninch JW, Santucci RA. Renal and ureteral trauma. In: Wein AJ, Kavoussi LR, Novick AC, Partin AW, Peters CA, editors. Campbell-Walsh urology. 9th ed. Philadelphia: Saunders; 2007. p. 1282-92.

5. Demirkesen O, Tunc B, Ozkan B. A rare complication of lumbar disk surgery: ureteral avulsion. Int Urol Nephrol 2006;38:459-61. 